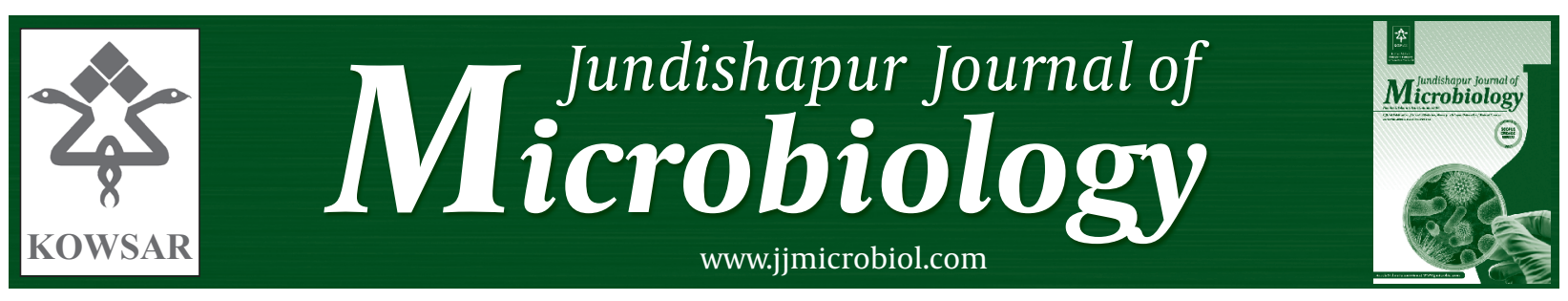

\title{
Pelvic Bone Hydatidosis
}

\author{
Hamid Reza Arti ${ }^{1^{*}}$, Maghsood Mohammadzade ${ }^{1}$ \\ ${ }^{1}$ School of Medicine, Ahvaz Jundishapur University of Medical Sciences, Ahvaz, IR Iran
}

\begin{tabular}{l}
\hline A R T I C L E I N F O \\
\hline Article type: \\
Case Report \\
\hline Article history: \\
Received: 21 Jan 2012 \\
Revised: 01 Mar 2012 \\
Accepted: 09 Apr 2012 \\
\hline
\end{tabular}
\begin{abstract}
A B S T R A C T
Hydatid disease is caused by Echinococcus spp. especially Echinococcus granulosus that is the most common cause of hydatid disease in humans. This disease occurs either through direct contact with infected dogs or indirectly from the ingestion of contaminated water or food with eggs of worms. The most common site in human is the liver (59-75\%), followed in frequency by lung (27\%), kidney (3\%) and bone (1-4\%). The authors report a case of the pelvic bone hydatidosis in a 27-years old patient, appearing with pain and a mass in the pelvic region.
\end{abstract}

\section{Keywords:}

Bone Cyst

Echinococcosis

Hydatid Cyst

Published by Kowsar Corp, 2012. cc 3.0.

Implication for health policy/practice/research/medical education:

This article emphasize hydatid cyst is a differential diagnosis of bone cystic lesions, especially in endemic areas and biopsies or aspiration of cyst should be avoided in such cases.

Please cite this paper as:

Arti HR, Mohammadzade M.Pelvic Bone Hydatidosis. JundishapurJ Microbiol. 2012;5(4):598-600. DOI:10.5812/jjm.4208

\section{Introduction}

Hydatid disease is still endemic in several regions including Iran (1-3).Though skeletal involvements are usually secondary to hepatic or pulmonary hydatidosis, but maybe, occurs as the primary disease. The most commonly affected sites in bone are the vertebrae, pelvis, and the skull. The vertebrae are the most commonly affected bones (50\%), followed by the pelvis (25\%) and the long bones (15-25\%) (4). This disease can present as a solitary or polycystic disease. In both types of hydatid cyst, pressure absorption of the bone, in addition thinning and fracturing and extension through the soft tissues occurs (5). Hydatid disease of the bone is often asymptomatic for a long duration and is usually detected after a sudden fracture, secondary infection or neurovascular impingement caused by compression $(6,7)$. Progressive changes may resemble tumor formation with an expansive cystic appearance. A definite preoperative diagnosis without histological examination is often difficult, as there are not pathognomonic signs. There are no specific radiographic signs in affected bone; in the later stages, lytic lesions with trabeculated pattern, with or without sclerosis May be seen. Radiographic findings, perhaps misdiagnosed as those of other lesions and immunologic test, are of limited value (8).

\section{Case Report}

A 27-years old woman presented with a three-month history of a pain and a mass in the pelvic region prominent in right lower quadrant extended to near symphysis pu-

\footnotetext{
* Corresponding author: Hamid Reza Arti, School of Medicine, Ahvaz Jundishapur University of Medical Sciences, Ahvaz, IR Iran. Tel: +98-6113387481, Fax: +986113387493,E-mail: hamidrezaarti@gmail.com permits unrestricted use, distribution, and reproduction in any medium, provided the original work is properly cited.
} 
bis. Pain relieved only by administration of narcotics (9). She first was referred to this center for tumor work-up and management of an aggressive tumor; but by paraclinical studies we found she may be affected by hydatidosis. Radiologic study revealed multiple lytic lesion of right superior and inferior pubic rami with no reactive sclerosis (Figure 1). MRI and CT scan showed also multiple cysts in bones of rami, ischium and their surrounded soft tissues (Figure 2). Bone hydatid disease lacks a typical clinical appearance and image characteristics on an $\mathrm{x}$ ray or CT scan are similar to those of tuberculosis, metastases and giant cell tumor or bone cysts. However, MRI does show distinctive diagnostic features of bone hydatid disease, especially in the spine (10) via illioinguinal approach, we saw many translucent cysts of Echinococcus in different sizes.

We extracted all cysts and resected involved bone of ramus as possible and the patient's mobility was preserved. We used formalin in the operative field to prevent extension of scolicies of Echinococcus.Histopathological evidences revealed characteristic trilamellar hydatid cyst

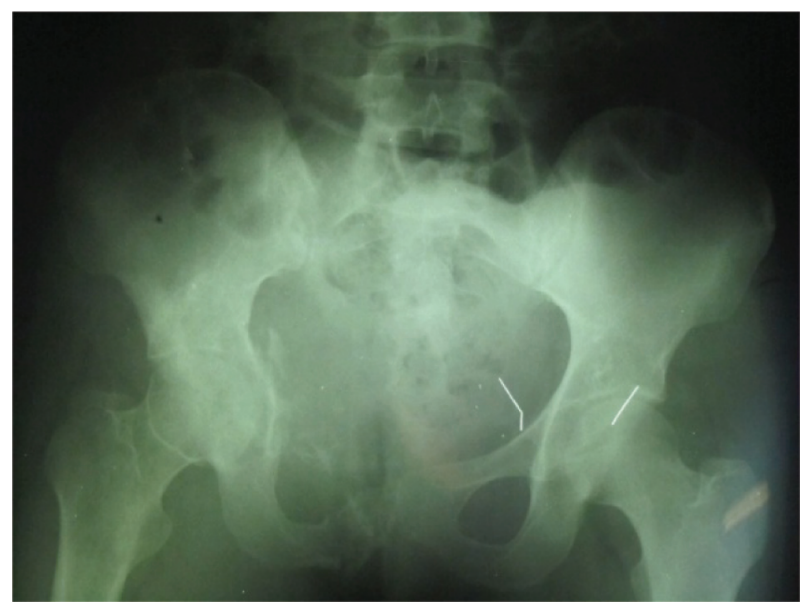

Figure 1. Destructive Area of Pelvic Bone Especially In Left Side of Hemipelvis

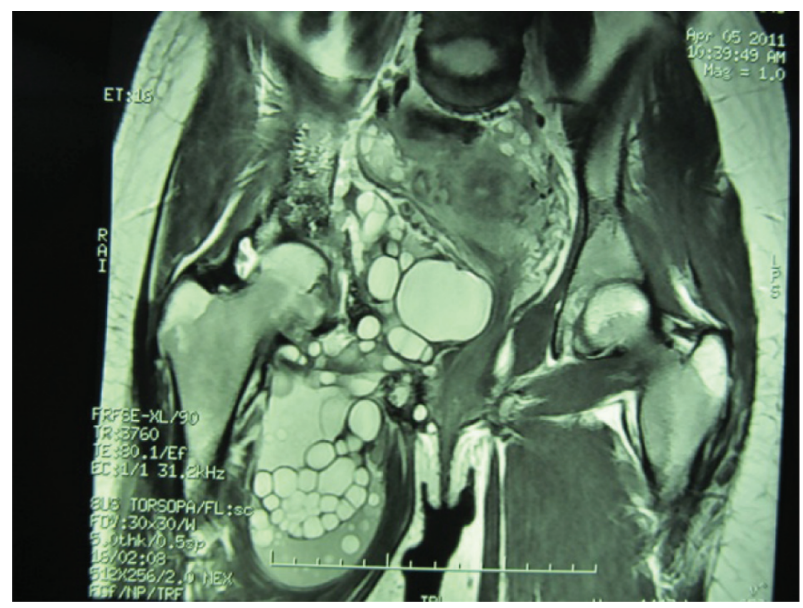

$\overline{\text { Figure 2. Daugther Cyst Affecting Bone in Bone and Soft Tissues of Pelvis }}$ wall and scolices of Echinococcus granulosus scattered amidst fragments of bone and erosion of bone were seen (Figure 3). An ultrasonography of the abdomen and Roentgenography of the chest was performed and did not reveal hydatid cyst in the lung or the liver. The patient was treated with albendazole for three cycles at a dose of $400 \mathrm{mg}$ twice a day for six weeks followed by a two- week rest without therapy. The patient was followed for 12 months with no recurrence of the lesion. The disease in the bone and joint begins once the blood-borne scolex settles there. The disease is a very slow process and thus, diseases are seldom diagnosed in the early period of infestation. There are fragmentation and conglomeration of the daughter cyst. The bone has mechanical resistance to cysts. Due to the pressure of the cyst, bone is absorbed and then cyst expands uniformly in the soft tissues. Intervertebral disc has the least resistance to growth $(11,12)$.

The disease must be suspected in cystic lesions of bone, especially in endemic areas such as Iran, as it may easily be misdiagnosed. It can mimic simple bone cyst, tuberculosis, aneurismal bone cyst, giant cell tumors, malignant fibrous histiocytoma, myeloma and chondrosarcoma (10). Diagnosis of bone hydatidosis is based on imaging and laboratory studies and sometimes is established after surgery $(13,14)$.

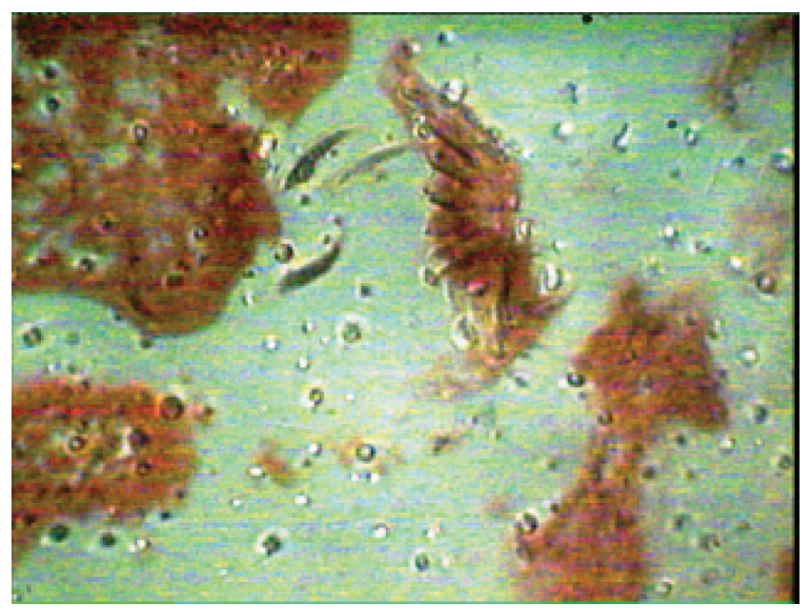

Figure 3. Photomicrograph $(100 \times)$ Showing Scolex in Pelvic Bone

Hydatid disease of bone is an infiltrating, diffuse, slow and progressive process, all of these characteristics justified the often-delayed diagnosis. Pelvic locations are particularly difficult to treat (15). Because of the poor results with medical treatment, bone hydatidosis must be treated with wide excision $(1,16)$. The best treatment for bone Echinococcosis is resection of the involved bone or to amputate it. Curettage and instilling solutions such as hypertonic saline, $1 \%$ formalin, or $0.5 \%$ silver nitrate have been tried. In suspected cases of Echinococcosis, diagnostic biopsy or aspiration is contraindicated. Operative management should include careful planning and meticulous technique to avoid spillage of the cyst contents, which may cause spread of the disease. 
OIf spillage occurs, the application of cetyltrimethylammonium bromide (Cetrimide), $2 \%$ formalin, or $1 \%$ iodine can reduce the danger of spreading (17). We used formalin in this patient. The purpose of this article is to alert orthopedic surgeons of this rare condition to emphasize the fact that the disease should be suspected in cystic lesions affecting any organ in the body, especially in endemic areas of the world and open and percutaneous needle biopsies should be avoided in such cases and is a differential diagnosis of cystic tumor in endemic areas.

\section{Acknowledgements}

We thankfully acknowledge the Deputy of Research Affairs at the Ahvaz Jundishapur University of Medical Sciences for the financial and technical support for this reaserch.

\section{Financial Disclosure}

None declared.

\section{Funding Support}

As stated in the acknowledgments financial and technical support of this reaserch was provided by the Deputy of Research Affairs of Ahvaz Jundishapur University of Medical Sciences.

\section{References}

1. Arti H, Darani HY. Fibular hydatid cyst. Indian J Orthop. 2007;41 (3):244-5.

2. Papanikolaou A. Osseous hydatid disease. Trans $R$ Soc Trop Med Hyg. 2008;102 (3):233-8.

3. Yuksel M, Demirpolat G, Sever A, Bakaris S, Bulbuloglu E, Elmas
N. Hydatid disease involving some rare locations in the body: a pictorial essay. Korean J Radiol. 2007;8 (6):531-40.

4. Calvo AM, Cires JM, Monton S, Sarasibar H, Lasanta P, Artazcoz FJ [Inguinal tumor: a rare occurrence of hydatid disease. A case report]. An Sist Sanit Navar. 2007;30 (3):475-9.

5. Khan JA, Devkota P, Acharya BM, Pradhan NM, Shreshtha S. Bony hydatid disease of superior pubic ramus with extension into pelvis and proximal thigh. J Nepal Med Assoc. 2008;47 (171):139-41.

6. Kalkan E, Cengiz SL, Cicek O, Erdi F, Baysefer A. Primary spinal in tradural extramedullary hydatid cyst in a child. J Spinal Cord Med. 2007;30 (3):297-300.

7. Patond KR, Srivastava SK, Kumar N. Musculoskeletal hydatidosis. India Pract. 1991;54:299-302.

8. Das S, Kalyani R, Kumar U, Kumar HM. A varied presentation of hydatid cyst: a report of four cases with review of literature. Indian J Pathol Microbiol. 2007;50 (3):550-2.

9. Arti HR, Mehdinasab SA. The comparison effects of intra-articular injection of different opioids on postoperative pain relieve after arthroscopic anterior cruciate ligament reconstruction: A randomized clinical trial study. J Res Med Sci. 2011;16 (9):1176-82.

10. Song XH, Ding LW, Wen H. Bone hydatid disease. Postgrad Med J. 2007;83 (982):536-42.

11. Mattern CJ, Gardner MJ, Grose A, Helfet DL. Case report: Echinococcus disease of the bone presenting as a femoral shaft nonunion. Clin Orthop Relat Res. 2007;458:220-5.

12. Proychev VI, Tzankov A. Solitary hydatid cyst in the tibia. Ann Trop Med Parasitol. 2007;101 (6):551-3.

13. Alldred AJ, Nisbet NW. Hydatid Disease of Bone in Australasia. J Bone Joint Surg Br. 1964;46:260-7.

14. Vasilevska V, Zafirovski G, Kirjas N, Janevska V, Samardziski M, Kostadinova-Kunovska S, et al. Imaging diagnosis of musculoskeletal hydatid disease. Prilozi. 2007;28 (2):199-209.

15. Gdoura F, Trigui M, Zribi W, Ellouze Z, Bouzidi R, Ayedi K, et al. Pelvic bone hydatidosis. Orthop Traumatol Surg Res. 2010;96 (1):85-9.

16. Zlitni M, Ezzaouia K, Lebib H, Karray M, Kooli M, Mestiri M. Hydatid cyst of bone: diagnosis and treatment. World J Surg. 2001;25 (1):75-82.

17. Mihalko MJ, Martinez SF. Tuberculosis and other unusual infection. In: Campbell WC, Canale ST, Beaty JH, editors. Campbell's operative orthopaedics. Philadelphia, Penns: Mosby/Elsevier; 2008. 